\title{
THE
}

\section{Middle school food environments and racial/ethnic differences in sugar-sweetened beverage consumption: Findings from the Healthy Choices study}

Tracy K. Richmond

Jennifer L. Spadano-Gasbarro

Courtney E. Walls

S. Bryn Austin

Mary L. Greaney

University of Rhode Island, mgreaney@uri.edu

Follow this and additional works at: https://digitalcommons.uri.edu/kinesiology_facpubs

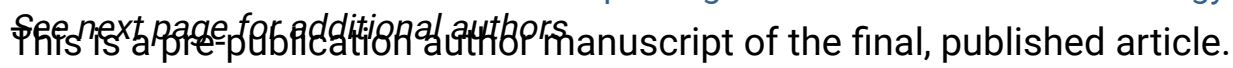

Creative Commons License (c) (i) (8)

This work is licensed under a Creative Commons Attribution-Noncommercial-No Derivative Works 4.0 License.

\section{Citation/Publisher Attribution}

Richmond, T. K., Spadano-Gasbarro, J. L., Walls, C. E., Austin, S. B., Greaney, M. L., Wang, M. L., Mezegebu, S., \& Peterson, K. E. (2013). Middle school food environments and racial/ethnic differences in sugarsweetened beverage consumption: Findings from the Healthy Choices study. Preventive Medicine, 57(5), 735-738. doi: 10.1016/j.ypmed.2013.09.001 Available at: https://doi.org/10.1016/j.ypmed.2013.09.001 accepted for inclusion in Kinesiology Faculty Publications by an authorized administrator of DigitalCommons@URI. For more information, please contact digitalcommons-group@uri.edu. 


\section{Authors}

Tracy K. Richmond, Jennifer L. Spadano-Gasbarro, Courtney E. Walls, S. Bryn Austin, Mary L. Greaney, Monica L. Wang, Solomon Mezegebu, and Karen E. Peterson 


\title{
Middle school food environments and racial/ethnic differences in sugar-sweetened beverage consumption: Findings from the Healthy Choices study
}

\author{
Tracy K. Richmond, MD, MPH ${ }^{\mathrm{a}}$, Jennifer L. Spadano-Gasbarro, PhD $^{\mathrm{b}}$, Courtney E. Walls, \\ $\mathrm{MPH}^{\mathrm{C}}$, S. Bryn Austin, ScD ${ }^{\mathrm{a}, \mathrm{d}}$, Mary L. Greaney, $\mathrm{PhD}^{\mathrm{e}}$, Monica L. Wang, MS, ScD ${ }^{\mathrm{d}}$, Solomon \\ Mezegebu, MS ${ }^{f}$, and Karen E. Peterson, ScD ${ }^{b, g}$ \\ aDivision of Adolescent and Young Adult Medicine, Children's Hospital Boston \\ bDepartment of Nutrition, Harvard School of Public Health, Boston, Massachusetts \\ ${ }^{\circ}$ Clinical Research Program, Children's Hospital Boston, Boston Massachusetts \\ dDepartment of Society, Human Development and Health, Harvard School of Public Health, \\ Boston, Massachusetts \\ eCenter for Community-Based Research, Dana Farber Cancer Institute, Boston, Massachusetts \\ fMassachusetts Department of Public Health \\ gHuman Nutrition Program, Department of Environmental Health Services, University of Michigan \\ School of Public Health, Ann Arbor, Michigan
}

\begin{abstract}
Background-Prior studies have demonstrated disproportionate clustering of fast food outlets around schools.
\end{abstract}

Purpose-To determine if racial/ethnic differences in middle school student self-reported sugarsweetened beverage (SSB) consumption is explained by differential distributions of food outlets surrounding their schools.

\begin{abstract}
Methods-Baseline (2005) data were analyzed from 18,281 middle school students in 47 Massachusetts schools participating in Healthy Choices, an obesity prevention program. Linear mixed effects models were used to examine the association of individual race/ethnicity and daily SSB consumption and the potential mediating effect of the density of food outlets (the number of fast food outlets and convenience stores in a $1500 \mathrm{~m}$ buffer area surrounding the school) on this association adjusting for individual and school demographics.
\end{abstract}

Results-More SSB consumption was reported by students of all racial/ethnic minority groups compared to their White peers except Asians. The density of fast food restaurants and convenience

\footnotetext{
(C) 2013 Elsevier Inc. All rights reserved

Corresponding Author: Tracy K. Richmond, MD, MPH Address: 300 Longwood Ave, LO-649, Boston, MA 02115 Telephone: 617 3555487 Fax: 6177300185 tracy.richmond@ childrens.harvard.edu.

Publisher's Disclaimer: This is a PDF file of an unedited manuscript that has been accepted for publication. As a service to our customers we are providing this early version of the manuscript. The manuscript will undergo copyediting, typesetting, and review of the resulting proof before it is published in its final citable form. Please note that during the production process errors may be discovered which could affect the content, and all legal disclaimers that apply to the journal pertain.

Conflict of interest statement: The authors have no conflicts of interest to disclose nor any corporate affiliations.

Conflict of Interest Statement The authors declare that there are no conflicts of interest to report.
} 
stores was not associated with individual SSB consumption $(\beta=0.001, \mathrm{p}=0.875)$ nor did it mediate the association of race/ethnicity and SSB consumption.

Conclusions-Racial and ethnic differences in SSB consumption among MA middle school students cannot be fully explained by the location of fast food restaurants and convenience stores.

\section{INTRODUCTION ${ }^{\star}$}

Child obesity remains one of the most significant public health problems in the US with Blacks and Hispanics disproportionately affected (Ogden et al, 2012). There are many behaviors linked to child/adolescent obesity, including consumption of sugar sweetened beverages (SSB) (Ludwig et al, 2001). Consumption of SSB by school-age children is pervasive with more than half of children/adolescents reporting daily SSB consumption (Babey et al, 2011). Black and Hispanic children consume more SSB than their White peers (Lasater et al, 2011; Taveras et al, 2010) amplifying their risk of weight gain, obesity, (Malik et al, 2006; Ludwig et al, 2001) and Type 2 Diabetes mellitus (Malik et al, 2010). Fast food restaurants and convenience stores may provide access and drive consumption especially given the evidence that fast food outlets cluster disproportionately around schools (Babey et al, 2011; Austin et al, 2005; Kwate and Loh, 2010; Zenk and Powell, 2008) and particularly schools with high concentrations of low-income and racial/ethnic minority students. (Kwate and Loh, 2010; Kestens and Daniel, 2010). Little is known about how the clustering impacts SSB consumption or contributes to racial/ethnic disparities (Davis and Carpenter, 2009; Powell et al, 2006; Sturm and Datar, 2005; Howard et al, 2011).

We aimed to assess whether: 1) self-reported SSB intake is higher in racial/ethnic minority middle school students than White middle school students; 2) racial/ethnic minority students attend schools with more food outlets nearby compared to Whites; 3 ) Proximity to more food outlets increases self-reported SSB consumption; 4) Density of food outlets surrounding the school mediates the relationship between race/ethnicity and self-reported SSB consumption.

\section{METHODS}

\section{Sample}

We used baseline data from our sample which was derived from $18,2816^{\text {th }}, 7^{\text {th }}$, and $8^{\text {th }}$ grade middle school students attending the 47 schools participating in the Healthy Choices (HC) study, a multi-component obesity intervention program in MA middle schools described elsewhere (Austin, et al, in press). Exclusions included: $5^{\text {th }}$ graders $(n=315)$; males reporting menses $(\mathrm{n}=246)^{\dagger}$; participants missing data on key variables including race/ ethnicity, age, gender, and SSB consumption $(\mathrm{n}=1,849)$. The final study sample was 18,281 males and females in grades $6-8$.

\section{Outcome Measures}

SSB consumption-The outcome variable was self-reported daily SSB consumption (servings/day). This variable was constructed from two questions: "In the past 7 days, how often did you drink Soda ("NOT DIET")?" and "In the past 7 days, how often did you drink flavored drinks?" Responses ranged from 'Never or less than 1 can or glass in the past 7 days' (coded as 0 ) to `3 or more cans or glasses per day (coded as 3 cans or glasses/day).' For

\footnotetext{
*Sugard-Sweetened Beverages (SSB); North American Industry Classification System (NAICS); Free and reduced lunch (FRL); Healthy Choices Study (HC)

${ }^{\dagger}$ There were males in this survey who responded yes to having had menses. This brought into question the veracity of their answers so we chose not to include them in our analytic sample.
} 
responses with a range the midpoint was taken (i.e., 2-4 cans/glasses in the past 7 days was counted as 3 cans/glasses in the past 7 days). The responses to the two beverage questions (soda and flavored drinks) were added and divided by 7 to convert the response detailing consumption over prior 7 days to daily SSB consumption.

\section{Predictor Variables}

Demographics-Individuals self-reported their age, gender, and race/ethnicity. Descriptors of the school demographics (percent White and percent eligible for free/reduced lunch (FRL)) were derived from National Center for Educational Statistics school-level demographic data (NCES). Due to the high correlation of these two variables $(a=0.77)$, the percent White was excluded from models.

Density of fast food outlets and convenience stores (food outlets)-The school addresses were geocoded and combined with a proprietary database, the Business Analyst, of all businesses surrounding the school. (ArcGIS) Using the North American Industry Classification System (NAICS) convenience stores and fast food outlets were identified and their density in a $1500 \mathrm{~m}$ buffer area (equivalent to a 15 minute walk) surrounding the school calculated (fast food outlets were pulled from the NAICS category 'limited service restaurants'). As a sensitivity analysis to insure that our choice of buffer size was not driving the lack of association, the association of having any fast food or convenience store within a $400 \mathrm{~m}$ and $1500 \mathrm{~m}$ buffer area (yes/no) and SSB consumption was also examined.

\section{Statistical Analyses}

All analyses were performed using Stata SE 11. We used a mediational analytic approach to test for the effects of the density of food outlets on the association of race/ethnicity and SSB consumption (Figure 1). Using linear mixed effects models with school as a random effect to account for non-independence of students clustered by school we examined the association of: 1) race/ethnicity and SSB consumption (Figure 1, c'); 2) race/ethnicity and density of food outlets (Figure 1, a); 3) density of food outlets and SSB consumption (Figure 1, b); 4) race/ethnicity and SSB consumption controlling for density of food outlets to test for a mediational effect (Figure 1, c). All models were adjusted for age, gender, and \% FRL. As a sensitivity analysis a similar series of analyses was performed with an indicator variable for having a food outlet (yes/no) in a $400 \mathrm{~m}$ and $1500 \mathrm{~m}$ buffer area.

\section{RESULTS}

Table 1 provides descriptors of the student population and the schools they attended. Figure 2 demonstrates variability in the density of food outlets surrounding participating schools (both available in supplementary data).

Table 2 shows the results corresponding to Figure 1, $\mathrm{c}^{\prime}$ and $\mathrm{c}$ of the mediational analysis. In Step 1 (c' in Figure 1, Model 1 in Table 2) all of the racial/ethnic groups with the exception of Asians have on average higher SSB consumption compared to their White peers. In Steps 2 and 3 ( $a$ and $b$ in Figure 1), we found no differences in density of food outlets between schools attended by Whites and other racial/ethnic groups nor did we find an association between density of food outlets and SSB consumption (data not shown). In Step 3 (c in Figure 1, Model 2 in Table 2), we found virtually no difference from Model 1 indicating no significant effect of the density of food outlets on the association between race/ethnicity and SSB consumption. Of note, students attending schools with a higher $\%$ of the student body eligible for FRL reported on average higher SSB consumption $(\beta=0.012, \mathrm{p}<0.001)$. 


\section{DISCUSSION}

All of the racial/ethnic minority groups self-reported on average higher consumption of SSB than their White peers but there was no difference in the density of food outlets surrounding their schools nor was there evidence of a mediating effect of food outlet density on the association between race/ethnicity and SSB consumption. No association was found between the density of food outlets and student self-reported SSB consumption. These findings add to the conflicting results to date examining associations between food outlets and dietary behaviors in students.

There are several possible explanations for the lack of association of density of food outlets and SSB consumption and lack of mediating effect of density of food outlets on the association of race/ethnicity and SSB. First, this study population was made up of middle school students who may have less ability to purchase SSB from food outlets independently. Additionally, we chose to examine the density of fast food restaurants and convenience stores and created an exhaustive list rather than focusing on a Top 10 list as other studies have done (Davis and Carpenter, 2009; Currie et al, 2010). This may have decreased the variability in density of food outlets across schools, thus making it more difficult to find an association between density and SSB consumption. However, we examined a different measure of access to food outlets: having at least one fast food outlet or convenience store within $400 \mathrm{~m}$ and $1500 \mathrm{~m}$, and still found no association.

\section{Strengths and Limitations}

Limitations include: 1) cross-sectional nature eliminating our ability to infer causality; 2) reliance on publicly available data to describe the density of food outlets, as has been done in other studies (Sturm, 2008; Davis and Carpenter, 2009; Currie et al, 2010) but possibly leading to mis-classification; 3) generalizability confined to Massachusetts; 4) reliance on self-report for our outcome; 5) numerous unmeasured school and neighborhood factors. We did not have information available regarding the students' home environments and access to food sources nearby. We also did not have information regarding individual socioeconomic status which is known to be correlated with SSB consumption (Han and Powell, 2013). However, our sample of schools were primarily neighborhood middle schools that tend to be reflective of the demographics and food environments of the students' neighborhoods of residence. Strengths include a large diverse population across many schools distributed throughout Massachusetts.

\section{CONCLUSION}

This study demonstrates the complexity in the relationship between location of food outlets and SSB consumption. Further research is needed to fully understand the implications of placement of convenience stores and fast food environments relative to schools and student SSB consumption.

\section{Acknowledgments}

Tracy Richmond is supported by the National Institutes of Health Career Development Award (NICHD K01 HD058042). S. Bryn Austin is supported by the Leadership Education in Adolescent Health Project Grant (T71 MC 00009-17) from the Maternal and Child Health Bureau, HRSA, US DHHS. Neither funding source participated in any way in the study or manuscript preparation.

\section{References}

[Accessed July 18, 2012] ArcGIS® software by Esri. Available at www.esri.com. 
Austin SB, Melly SJ, Sanchez BN, Patel A, Buka S, Gortmaker SL. Clustering of fast-food restaurants around schools: a novel application of spatial statistics to the study of food environments. Am J Public Health. 2005; 95:1575-81. [PubMed: 16118369]

Austin SB, Spadano-Gasbarro JL, Greaney ML, Blood EA, Hunt AT, Richmond TK, Wang ML, Mezgebu S, Osganian SK, Peterson KE. Effect of the Planet Health intervention on eating disorder symptoms in a large-scale dissemination to Massachusetts middle schools. Prev Chronic Dis. In press.

Babey SH, Wolstein J, Diamant AL. Food environments near home and school related to consumption of soda and fast food. Policy Brief UCLA Cent Health Policy Res PB. 2011; 2011-6:1-8.

Currie J, Della Vigna S, Moretti E, Pathania V. The effect of fast food restaurants on obesity and weight gain. Am Econ J: Econ Pol. 2010; 2:34-68.

Davis B, Carpenter C. Proximity of fast-food restaurants to schools and adolescent obesity. Am J Public Health. 2009; 99:505-510. [PubMed: 19106421]

Han E, Powell LM. Consumption patterns of sugar-sweetened beverages in the United States. J Acad Nutr Diet. 113:43-53. [PubMed: 23260723]

Howard PH, Fitzpatrick M, Fulfrost B. Proximity of food retailers to schools and rates of overweight ninth grade students: an ecological study in California. BMC Public Health. 2011; 11:68. [PubMed: 21281492]

Kestens Y, Daniel M. Social inequalities in food exposure around schools in an urban area. Am J of Prev Med. 2010; 39(1):33-40. [PubMed: 20537844]

Kwate NO, Loh JM. Separate and unequal: the influence of neighborhood an school characteristics on spatial proximity between fast food and schools. Prev Med. 2010; 51:153-6. [PubMed: 20457178]

Lasater G, Piernas C, Popkin BM. Beverage patterns and trends among school-aged children in the US, 1989-2008. Nut J. 2011; 10:103.

Ludwig DS, Peterson KE, Gortmaker SL. Relation between consumption of sugar-sweetened drinks and childhood obesity: a prospective observational analysis. Lancet. 2001; 357:505-508. [PubMed: 11229668]

Malik VS, Schulze MB, Hu FB. Intake of sugar-sweetened beverages and weight gain: a systematic review. Am J ClinNut. 2006; 84:274-288.

Malik VS, Popkin BM, Bray GA, Despres JP, Hu FB. Sugar-sweetened beverages, obesity, type 2 diabetes mellitus, and cardiovascular disease risk. Circulation. 2010; 121:1356-64. [PubMed: 20308626]

National Center for Educational Statistics. [Accessed May 7, 2012] Common Core of Data Build a Table. http://nces.ed.gov/ccd/bat/.

[Accessed July 18, 2012] North American Industry Classification. Available at http://www.naics.com/ search.htm.

Powell LM, Auld C, Chaloupka FJ, O'Malley PJ, Johnson FD. Access to fast food and food prices: relationship with fruit and vegetable consumption and overweight among adolescents. Adv Health Econ Health Serv Res. 2006; 17:23-48. [PubMed: 19548547]

Sturm R, Datar A. Body mass index in elementary school children, metropolitan area food prices and food outlet density. Public Health. 2005; 119:1059-68. [PubMed: 16140349]

Sturm R. Disparities in the food environment surrounding US middle and high schools. Public Health. 2008; 122:681-90. [PubMed: 18207475]

Taveras EM, Gillman MW, Kleinman K, Rich-Edwards JW, Rifas-Shiman SL. Racial/ethnic differences in early-life risk factors for childhood obesity. Pediatrics. 2010; 125:686. [PubMed: 20194284]

Zenk SN, Powell LM. United States secondary schools and food outlets. Health Place. 2008; 14:33646. [PubMed: 17881277] 

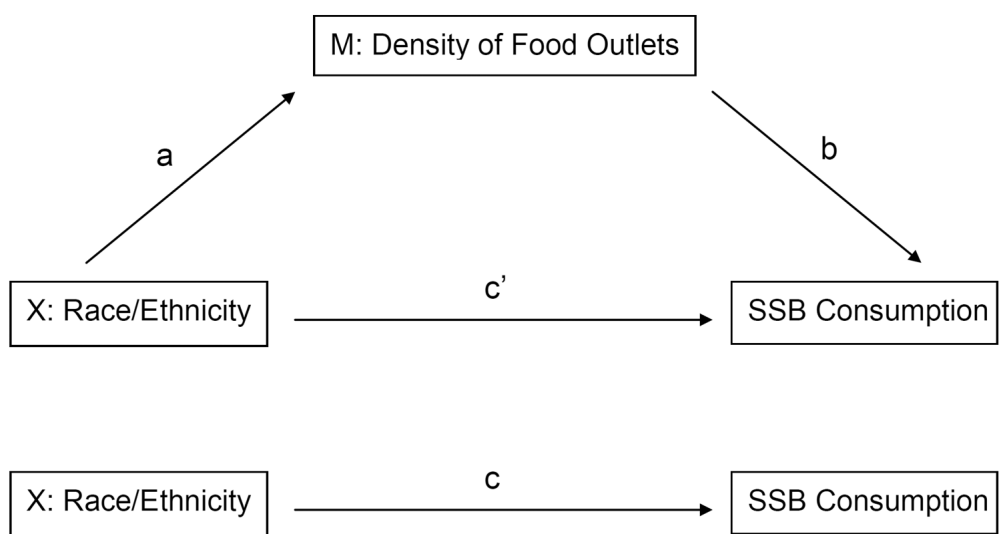

Figure 1.

Mediational analytic approach to understanding the effect of density of food outlets on the association between individual race/ethnicity and self-reported sugar sweetened beverage consumption in Massachusetts middle school students, 2005 


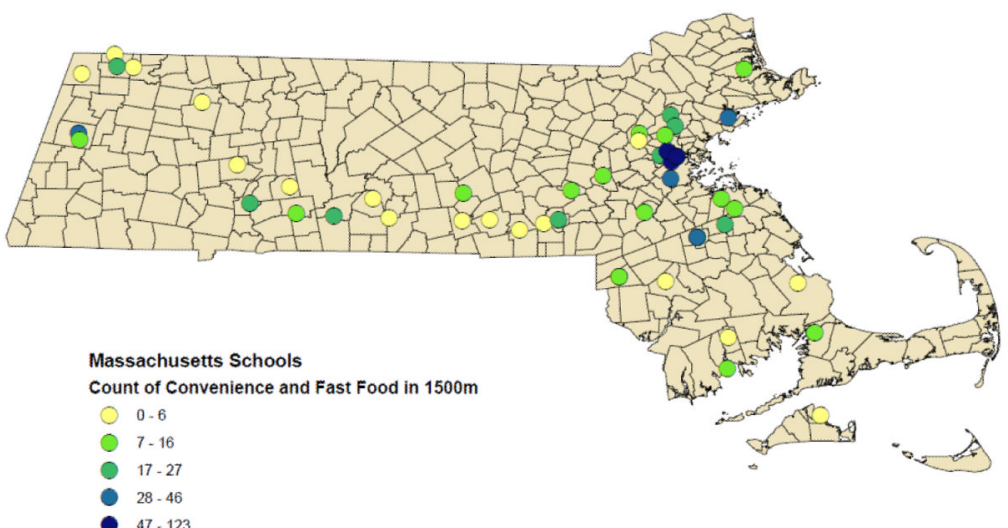

Figure 2.

Distribution of food outlets in buffer area surrounding Healthy Choices participating middle schools in Massachusetts, 2005 
Table 1

Demographics of the MA middle schools students participating in Healthy Choices, 2005

\begin{tabular}{|l|c|}
\hline & N (percent) \\
\hline INDIVIDUAL-LEVEL VARIABLES & \\
\hline Race/ethnicity & \\
\hline American Indian/Alaskan Native & $226(1.2)$ \\
\hline Asian & $772(3.9)$ \\
\hline Black/African-American & $880(4.5)$ \\
\hline Hispanic & $1327(6.7)$ \\
\hline Pacific Islander & $87(0.4)$ \\
\hline White/Caucasian & $15095(76.7)$ \\
\hline Multi-racial & $1294(6.6)$ \\
\hline Female gender & $10189(50.8)$ \\
\hline Mean age & $12.3(0.96)$ \\
\hline Mean daily sugar sweetened beverage consumption (standard deviation) & $1.12(1.21)$ \\
\hline SCHOOL-LEVEL VARIABLES & \\
\hline Mean percent of student body that is White (standard deviation) & $68.2(22.8)$ \\
\hline Mean percent of student body that is eligible for free/reduced lunch & $26.8(20.0)$ \\
\hline
\end{tabular}




\section{Table 2}

The associations of individual race/ethnicity and density of food outlets with sugar-sweetened beverage consumption in MA middle school students participating in Healthy Choices, 2005

\begin{tabular}{|l|c|l|c|c|}
\hline & $\begin{array}{c}\text { Model 1 (c). Examining } \\
\text { the association of race/ } \\
\text { ethnicity and SSB } \\
\text { consumption }(\boldsymbol{\beta} \\
\text { coefficients) }\end{array}$ & $\begin{array}{c}\text { p-value } \\
\text { Model 2 (c'). Examining the } \\
\text { mediational effect of the } \\
\text { density of food outlets on the } \\
\text { association of race/ethnicity } \\
\text { and SSB consumption }(\beta \\
\text { coefficients) }\end{array}$ & p-value \\
\hline Race/ethnicity & & & & \\
\hline Alaskan Native/American Indian & $0.30(0.083)$ & $<0.001$ & $0.30(0.083)$ & $<0.001$ \\
\hline Asian & $-0.16(0.045)$ & $<0.001$ & $-0.16(0.045)$ & $<0.001$ \\
\hline Black/African-American & $0.42(0.044)$ & $<0.001$ & $0.42(0.044)$ & $<0.001$ \\
\hline Hispanic & $0.26(0.038)$ & $<0.001$ & $0.26(0.038)$ & $<0.001$ \\
\hline Multi-Racial & $0.11(0.035)$ & 0.003 & $0.11(0.035)$ & 0.003 \\
\hline Pacific Islander & $0.68(0.127)$ & $<0.001$ & $0.68(0.127)$ & $<0.001$ \\
\hline White & 0.00 & $R E F$ & 0.00 & $R E F$ \\
\hline Age & $0.11(0.009)$ & $<0.001$ & $0.11(0.009)$ & $<0.001$ \\
\hline Female & $-0.29(0.017)$ & $<0.001$ & $-0.29(0.017)$ & $<0.001$ \\
\hline $\begin{array}{l}\text { Percent of student body eligible for free and } \\
\text { reduced lunch }\end{array}$ & $0.01(0.001)$ & $<0.001$ & $0.01(0.001)$ & $<0.001$ \\
\hline $\begin{array}{l}\text { Density of fast food outlets and convenience } \\
\text { stores in 1.5km buffer area surrounding school }\end{array}$ & ------- & ----- & $0.0001(0.001)$ & 0.875 \\
\hline
\end{tabular}

